\title{
Unsuccessful clinical outcomes: Sometimes the stepping stones toward valuable innovation
}

\author{
Kyle W. Riggs, MD, and David L. S. Morales, MD
}

From the Department of Cardiothoracic Surgery, Cincinnati Children's Hospital Medical Center, Cincinnati, Ohio.

Disclosures: D.L.S.M. is a consultant and instructor for Berlin Heart, Inc; a proctor and consultant for SynCardia, Inc; a national primary investigator for the 50/50cc SynCardia TAH FDA trial; a consultant for Medtronic Inc (HeartWare Division); and a consultant for Abbott Medical Inc (Thoratec Division). The remaining author has nothing to disclose with regard to commercial support.

Received for publication Aug 28, 2018; accepted for publication Aug 28, 2018; available ahead of print Oct 8, 2018.

Address for reprints: Kyle W. Riggs, MD, 3333 Burnet Ave, Cincinnati, OH 45229 (E-mail: kyle.riggs@cchmc. org).

J Thorac Cardiovasc Surg 2019;157:356-7

$0022-5223 / \$ 36.00$

Copyright (c) 2018 by The American Association for Thoracic Surgery

https://doi.org/10.1016/j.jtcvs.2018.08.067

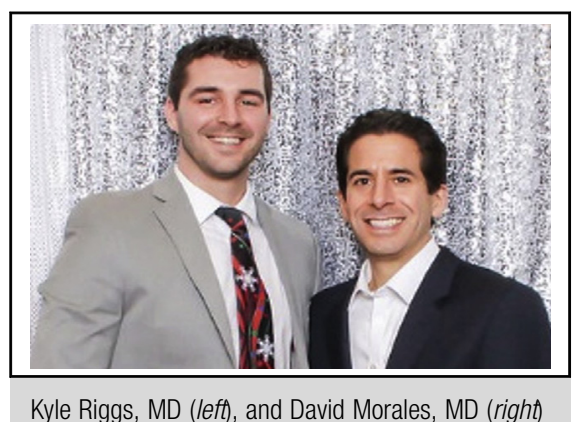

Kyle Riggs, MD (left), and David Morales, MD (right)

Central Message

Modifications to implantation of the total artificial heart are necessary in the Fontan population, but an ideal strategy is yet to be accepted.

See Article page 353
In this issue of the Journal, Woods and colleagues ${ }^{1}$ present an innovative solution for the implantation of the total artificial heart (TAH; SynCardia, Tucson, Ariz) in patients with a Fontan circulation. Although the literature is typically full of successful case reports, important breakthroughs often come from unsuccessful ventures. We therefore applaud Woods and colleagues ${ }^{1}$ for reporting this disappointing outcome in sharing their innovative technique. With only 6 TAHs implanted in patients with Fontan circulations worldwide (personal communication, SynCardia) and only a single previous report in the literature, TAH application to the Fontan circulation is in early development. $^{2}$

One recurrent issue for our field is waiting until patients are too ill before applying technology to a new, difficult patient cohort. In this case, the TAH was implanted in a very challenging, vasoplegic patient listed for combined heart-liver transplant only after a failed attempt of ventricular assist device therapy resulting in extracorporeal membrane oxygenation support. As noted by Woods and colleagues, ${ }^{1}$ had the TAH been the initial strategy, perhaps the outcome might have been better. The TAH's hemodynamic profile may make it an ideal device for resuscitating the patient with a late failing Fontan circulation who has poor cardiac output and venous congestion. Unlike a systemic ventricular assist device or even transplantation, it can immediately provide a supraphysiologic cardiac index $\left(>4 \mathrm{~L} / \mathrm{min} / \mathrm{m}^{2}\right.$ ) with a central venous pressure less than $6 \mathrm{~mm} \mathrm{Hg}$. This low central venous pressure potentially allows the patient with a Fontan circulation to have reversal of protein-losing enteropathy, congestive hepatopathy, congestive renal insufficiency, and other conditions. A second point is that the atria are often quite thickened and fibrosed in patients with a chronically failing Fontan circulation. This case demonstrated that the fibrous atrioventricular skeleton is not necessary to secure the TAH ventricles. The report excellently depicts and describes the technique necessary to allow expansion and bisection of the common atrium for TAH implantation. Notably, this technique is applicable to a variety of congenital heart anatomies if the integrity of the atrium is sufficiently strong. Third, the use of a fenestration may not have been necessary. Placement of a fenestration in patients with a Fontan circulation supported with a systemic ventricular assist device is becoming commonly practiced, because flow across the usually abnormal vasculature of these patients is often in question. For the TAH, however, which does not rely on passive flow to fill and has a wellknown ability to pump through quite high resistances, the use of a fenestration may not be advantageous and may be disadvantageous (increased stroke risk). Finally, an issue often discussed with TAH use in patients with a Fontan circulation is the negative pressure set by the device possibly causing the atrium or other right-sided capacitance chamber to collapse; however, this will not happen. The negative pressure of about 8 to $14 \mathrm{~mm} \mathrm{Hg}$ that one sets on the controller is used to evacuate air from the tubing and air chamber, not to generate actual negative pressure in the atrium. Issues of inflow chambers collapsing or of inadequate filling are thus related to compression by the device or tamponade. As more patients with a Fontan circulation reach end-stage heart 
failure, it will be interesting to observe the application of TAHs in this challenging patient population. This technical innovation by Woods and colleagues ${ }^{1}$ represents a valuable stepping stone in the development of a successful strategy for TAH support of patients with a Fontan circulation.

\section{References}

1. Woods RK, Neibler R, Kindel S, Troshynski T, Joyce LD, Hraska V. A new method for implanting a total artifical heart in the patient with a Fontan circulation. J Thorac Cardiovasc Surg. 2019;157:353-5.

2. Rossano JW, Goldberg DJ, Fuller S, Ravishankar C, Montenegro LM, Gaynor JW Successful use of the total artificial heart in the failing Fontan circulation. Ann Thorac Surg. 2014;97:1438-40. 